\title{
NDRG1 suppresses vasculogenic mimicry and tumor aggressiveness in gastric carcinoma
}

\author{
XUEYI DONG ${ }^{1,2}$, YUHENG HONG ${ }^{3}$, HUIZHI SUN ${ }^{1}$, CHEN CHEN $^{1}$, XIULAN ZHAO $^{1,2}$ and BAOCUN SUN ${ }^{1,2,4}$ \\ ${ }^{1}$ Department of Pathology, Tianjin Medical University, Tianjin 300070; \\ ${ }^{2}$ Department of Pathology, General Hospital of Tianjin Medical University, Tianjin 300052; \\ ${ }^{3}$ School of Medical Imaging, Tianjin Medical University, Tianjin 300070; \\ ${ }^{4}$ Department of Pathology, Tianjin Medical University Cancer Institute and Hospital, Tianjin 300060, P.R. China
}

Received September 6, 2018; Accepted June 24, 2019

DOI: $10.3892 / \mathrm{ol} .2019 .10642$

\begin{abstract}
N-myc downstream regulated gene 1 (NDRG1) has been well characterized as a suppressor of metastasis in numerous types of carcinoma. NDRG1 inhibits the metastatic progression of cancer cells via its inhibitory effects on a wide variety of cellular signaling pathways. Vasculogenic mimicry (VM) refers to the unique ability of aggressive tumor cells to mimic the pattern of embryonic vasculogenic networks, and is the main reason for the poor prognosis and failure of antivascular therapy in gastric carcinoma (GC). Tumor cells can mimic the function of endothelial cells to exhibit VM through epithelial-mesenchymal transition (EMT). However, the potential function of NDRG1 in metastatic GC progression in patients has not yet been fully elucidated. To date, data regarding the function of NDRG1 in VM formation in GC have not been reported. The aim of the present study was to elucidate these unknown areas. To this end, 228 samples of human GC were used to identify the protein expression levels of NDRG1, VM-associated proteins and EMT-associated proteins via immunohistochemistry, and their clinical significance was assessed. In addition, the data of 415 patients with GC were collected from The Cancer Genome Atlas database. A functional enrichment analysis concerning NDRG1 was performed using Metascape and the Gene Set Enrichment Analysis (GSEA). In conclusion, the results of the present study indicate that NDRG1 is negatively correlated with poor prognosis through suppression of VM formation in GC. The results of the present study demonstrated that NDRG1 decreases EMT-associated protein expression and that HER2 expression may serve a significant role in this process. The
\end{abstract}

Correspondence to: Professor Baocun Sun, Department of Pathology, Tianjin Medical University, 22, Qixiangtai Road, Tianjin 300070, P.R. China

E-mail: baocunsun@aliyun.com

Key words: gastric carcinoma, vasculogenic mimicry, N-myc downstream regulated gene 1, epithelial-mesenchymal transition, human epidermal growth factor receptor 2
Metascape and GSEA results also indirectly support this conclusion. The present study discusses the status NDRG1 as a prognostic and selective biomarker in GC, as well as current and future NDRG1-targeted therapies.

\section{Introduction}

Gastric carcinoma (GC) is the fifth most common malignant tumor and the second most common cause of cancer-associated mortality worldwide (1). Diagnosis and treatment methods for GC have improved each year, but the prognosis for patients remains poor. GC recurrence and metastasis remain the most prevalent causes of poor long-term survival (2).

The growth and metastasis of tumors requires an adequate blood supply. However, antivascular therapies have failed to improve the survival time of patients with late-stage GC. Additionally, it has been hypothesized that anti-angiogenesis therapy may induce vasculogenic mimicry (VM) formation $(3,4)$, a bloody supply pattern formed without the participation of endothelial cells. Therefore, VM may serve an important role in the development of GC, and may be the main cause of anti-angiogenic treatment failure.

VM was first described by Maniotis et al (5). Currently, VM has been demonstrated in numerous types of malignant solid tumor (6-9). VM provides a blood supply to tumors at the early stages of tumorigenesis, as well as a pathway for tumor metastasis. Furthermore, preliminary research has demonstrated that patients with GC with VM have shorter survival times and higher rates of metastasis than patients with GC without VM (9).

$\mathrm{N}$-myc downstream regulated gene 1 (NDRG1) serves an inhibitory role in the migration, invasion and metastasis of numerous different types of tumor by regulating epithelial-mesenchymal transition (EMT) or downregulating the erythroblastic leukemia viral oncogene homolog (ErbB) family of receptors $(10,11)$. However, whether the inhibitory effect of NDRG1 involves EMT and human epidermal growth factor 2 (HER2) in GC has not yet been fully elucidated. Furthermore, EMT has been confirmed to serve a key role in VM formation in a previous, preliminary study (12). At the same time, the NDRG1 protein inhibits angiogenesis in a number of solid tumors by inhibiting vascular endothelial 
growth factor (13). However, to the best of our knowledge, no studies have reported the inhibition of angiogenesis by NDRG1 or the function of NDRG1 in VM formation in GC.

The present study, therefore, investigated the role of NDRG1 in VM formation in patients with GC. The results of the present study may reveal a new functional role of NDRG1 in GC and may provide insights into the development of anti-angiogenic GC drugs.

\section{Materials and methods}

Patient samples. In total, 228 human GC tissue specimens were collected from patients who underwent surgical resection between January 2002 and December 2012 at the Tianjin Medical University Cancer Institute and Hospital (Tianjin, China). The age range of patients was $28-82$ years. GC tumor tissue samples were collected from patients who had not received chemotherapy, radiotherapy or surgical treatment of prior to surgery. All GC specimens were formalin fixed and paraffin embedded. The histopathological diagnosis was confirmed by trained pathologists according to the World Health Organization histological classification of stomach tumors. Detailed pathological and clinical data, such as age, sex, tumor size, histological differentiation, pathological stage, Lauren type, and metastasis and recurrence, were collected for all samples. Ethical approval was obtained from the Ethics Committee of Tianjin Medical University (Tianjin, China). Written informed consent was obtained from each patient. The privacy rights of human subjects were maintained.

Immunohistochemical and histochemical double-staining methods. All GC tissues were fixed in $10 \%$ neutral formalin for $24 \mathrm{~h}$ at room temperature, and paraffin embedded. Specimens were sectioned into $4 \mu \mathrm{m}$ sections. Sections were deparaffinized with xylene, rehydrated with a decreasing gradient of ethanol (100-80\%), and endogenous peroxidase activity was blocked with $3 \%$ hydrogen peroxide in $100 \%$ methanol for $30 \mathrm{~min}$ at room temperature. The sections were rehydrated and washed with PBS and pretreated with $0.01 \mathrm{M}$ citrate buffer (pH 6.0) or EDTA buffer ( $\mathrm{pH} 9.0$ ) for $15 \mathrm{~min}$ at $100^{\circ} \mathrm{C}$ in a microwave oven. Following blocking of non-specific binding sites using normal goat serum (cat. no. ZLI-9022; OriGene Technologies, Inc.) for $30 \mathrm{~min}$ at room temperature, the sections were incubated overnight at $4{ }^{\circ} \mathrm{C}$ with rabbit polyclonal anti-NDRG1 (1:400; ab124689; Abcam), mouse monoclonal anti-cluster of differentiation (CD) 34 (1:550; Zm-0046; OriGene Technologies, Inc.), rabbit polyclonal anti-vascular endothelial (VE)-cadherin (1:400 dilution, ab33168, Abcam), mouse polyclonal anti-HER2 (1:200 dilution, ZA-0023, OriGene Technologies, Inc.), rabbit polyclonal anti-Snail (1:200; ab180714; Abcam), rabbit polyclonal anti-Twist1 (1:100; Sc-15393; Santa Cruz Biotechnology, Inc.), rabbit polyclonal anti-epithelial (E)-cadherin (1:100; Sc-7870; Santa Cruz Biotechnology, Inc.) and rabbit polyclonal anti-vimentin (1:100; ab92547; Abcam). The sections were then rinsed with PBS, and super-sensitivity S-P IHC secondary antibodies kit (cat. no PV6001, anti-Rabbit; cat. no. PV6002, anti-Mouse; OriGene Technologies, Inc.) was applied to the sections at room temperature for $1 \mathrm{~h}$. The sections were stained with

Table I. Clinical data of patients with gastric cancer.

\begin{tabular}{lccc}
\hline & $\begin{array}{c}\text { Alive } \\
(\mathrm{n}=92)\end{array}$ & $\begin{array}{c}\text { Deceased } \\
(\mathrm{n}=131)\end{array}$ & $\begin{array}{c}\text { Total } \\
\left(\mathrm{n}=228^{\mathrm{a}}\right)(\%)\end{array}$ \\
\hline
\end{tabular}

\section{Sex}

\section{Female}

Male

Age, years

$<60$

$\geq 60$

Tumor size, $\mathrm{cm}^{3}$

$<3$

$\geq 3$

Histological differentiation

I/II

III/IV

TNM stage

I/II

III/IV

Lymphatic metastasis

Positive

Negative

Distant metastasis

Positive

Negative

Lauren type

Intestinal

Diffuse

Metastasis and recurrence

\begin{tabular}{lrrr} 
Positive & 8 & 95 & $105(46.1)$ \\
Negative & 84 & 36 & $123(54.0)$ \\
\hline
\end{tabular}

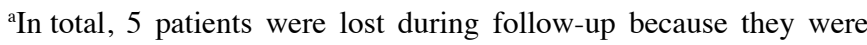
unreachable. TNM, Tumor-Node-Metastasis.

3,3'-diaminobenzidine chromogen for 10-15 $\mathrm{min}$ at room temperature and washed with distilled water.

Following immunohistochemical staining for CD34, the sections were washed with distilled water for $5 \mathrm{~min}$ and incubated with periodic acid for $10 \mathrm{~min}$ and with Schiff reagent for $15 \mathrm{~min}$. Finally, all sections were counterstained with hematoxylin at $37^{\circ} \mathrm{C}$ for $2 \mathrm{~min}$, dehydrated by increasing gradient of ethanol (80-100\%) and mounted on coverslisps with Neutral gum (OriGene Technologies, Inc.).

Gastric mucosa membrane adjacent to the GC tissues was used as a positive control for PBS staining. PBS was used in place of the primary antibodies as a negative control. Normal tissue sections were used as a positive control according to the manufacturer's protocol for each antibody supplier. All sections were observed and analyzed under light microscope (magnification, $\mathrm{x} 400$ ) by two pathologists. The expression of each marker was assessed semi-quantitatively according to the number of cells that stained positive and the intensity of immunostaining in individual tumor 


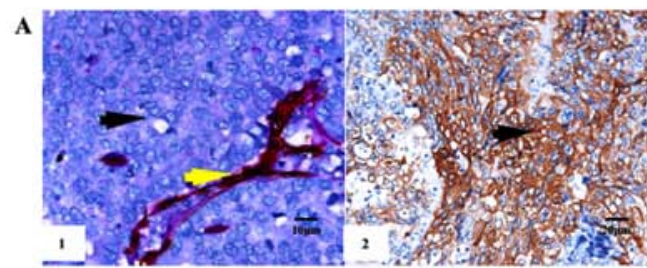

CD34/PAS (X400)

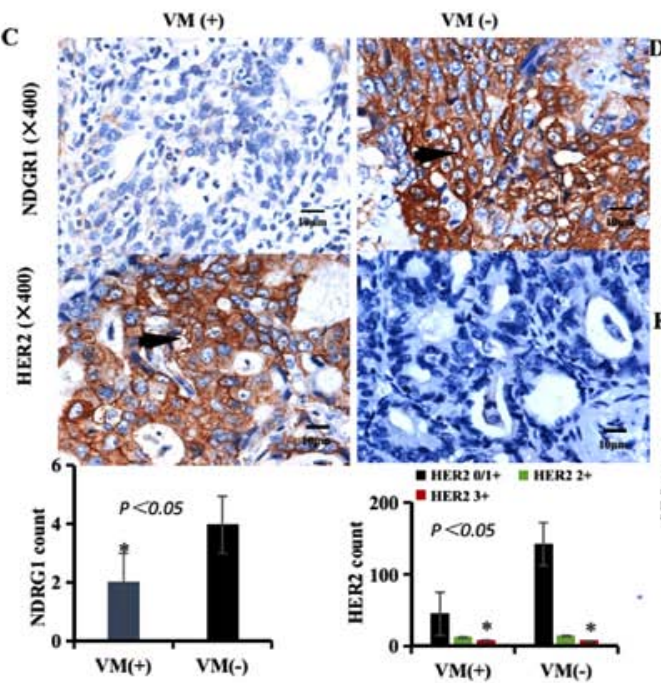

H

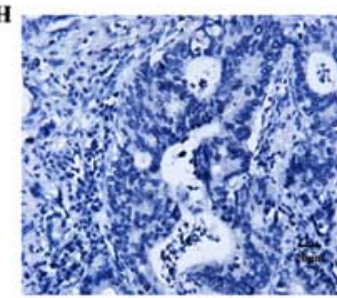

HER2 - $(\times 200)$

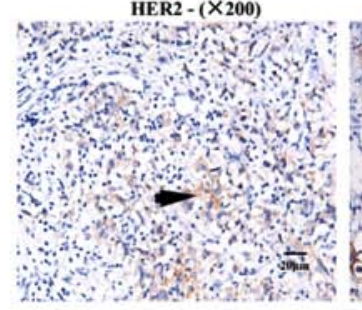

HER2 2+ ( $\times 200)$

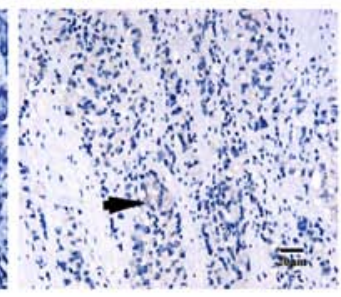

HER2 $1+(\times 200)$

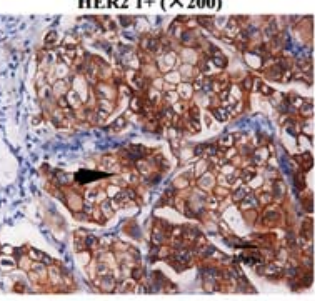

HER2 $3+(\times 200)$
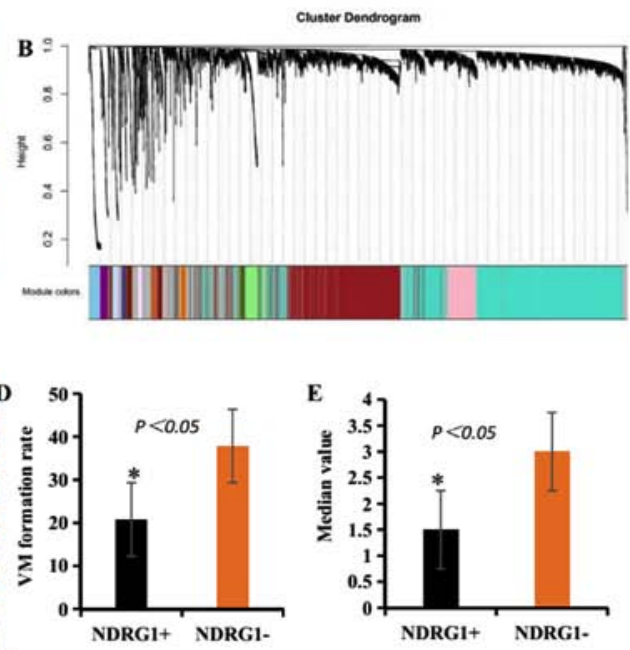

G
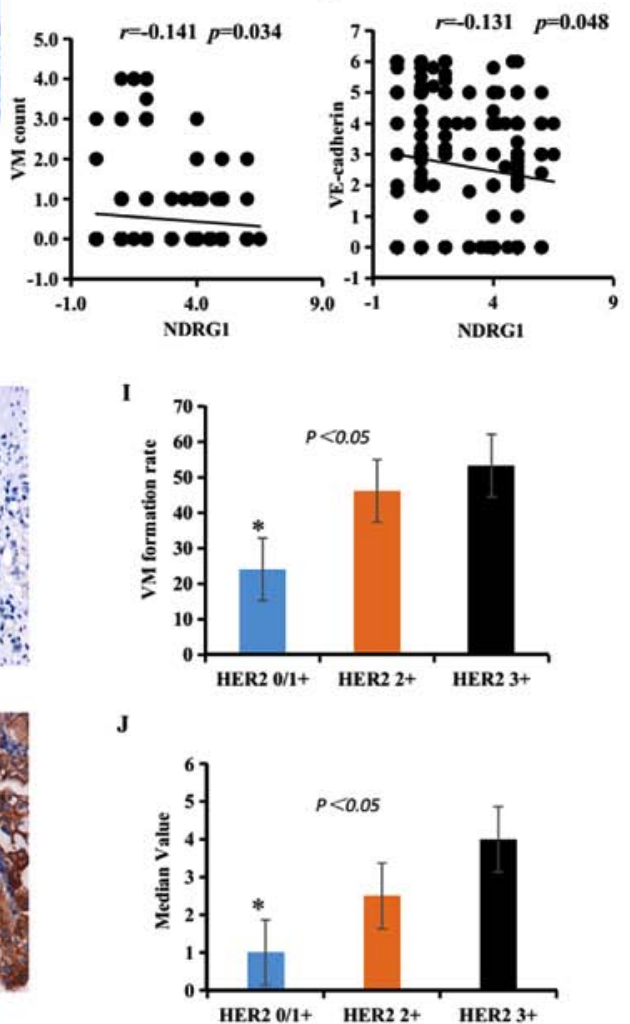

Figure 1. Associations between NDRG1 expression, HER2 expression and VM in GC specimens. (A/left panel) Identification of VM (black arrow, CD34-negative and PAS-positive cells) and EDV (yellow arrow, CD34-positive and PAS-positive cells) in GC specimens. Scale bar, $10 \mu \mathrm{m}$. Magnification, $\mathrm{x}$ 400. (A/right panel) IHC staining of NDRG1 expression. Brown particles were present in the cytoplasm and membranes of GC cells (black arrow). Scale bar, $20 \mu \mathrm{m}$. Magnification, x200. (B) Gene dendrogram obtained by average linkage hierarchical clustering. Different gene modules were obtained according to the segmentation results of the set standard, which were represented by branches of the Dynamic Tree Cut and different colors. A weighted correlation network analysis revealed that overall gene expression data corresponded to an overview of aggregation in the patients with GC. (C) IHC staining of NDRG1 and HER2 expression in VM-positive (left images) and VM-negative samples (right images) expression. Scale bar, $10 \mu \mathrm{m}$. Magnification, x400. (D) Rate of VM formation in different NDRG1 expression groups. (E) Median value of the VM count in different NDRG1 expression groups. (F) Correlation between NDRG1 expression and VM count using Pearson's correlation. (G) Correlation between NDRG1 expression and VE-cadherin expression using Pearson's correlation. (H) IHC staining of HER2 expression. Brown particles were present in the membrane of GC cells (black arrow). Scale bar, $20 \mu \mathrm{m}$. Magnification, $\mathrm{x} 200$. . (I) Rate of VM formation in different HER2 expression groups. (J) Median value of VM count in different HER2 expression groups. *P<0.05. EDV Endothelium-dependent blood vessels; GC, gastric carcinoma; HER2, human epidermal growth factor receptor 2; IHC, immunohistochemistry; NDRG1, N-myc downstream regulated gene 1; PAS, periodic acid-Schiff; VM, vasculogenic mimicry.

cells (14). For HER2, only immunoreactivity in the GC cell membrane was evaluated (15).

Periodic acid-Schiff (PAS)-Alcian blue staining protocol. Tissue sections were deparaffinized as aforementioned, washed with distilled water and then incubated for 10 min with Alcian blue buffer at room temperature. The sections were then washed with distilled water for $5 \mathrm{~min}$, incubated with periodic acid for $10 \mathrm{~min}$ at room temperature and washed with distilled water again. Sections were incubated with Schiff reagent for $15 \mathrm{~min}$ at 
Table II. Association between NDRG1 or VM and the clinicopathological parameters with gastric carcinoma.

\begin{tabular}{|c|c|c|c|c|c|c|c|c|}
\hline \multirow[b]{2}{*}{ Variable } & \multicolumn{4}{|c|}{ Tissue samples } & \multicolumn{4}{|c|}{ Tissue samples } \\
\hline & $\begin{array}{l}\text { NDRG1 } \\
(\mathrm{n}=125)\end{array}$ & $\begin{array}{l}\text { Non-NDRG1 } \\
\quad(\mathrm{n}=103)\end{array}$ & $\chi^{2}$ & P-value & $\begin{array}{c}\mathrm{VM} \\
(\mathrm{n}=65)\end{array}$ & $\begin{array}{c}\text { Non-VM } \\
(n=163)\end{array}$ & $\chi^{2}$ & P-value \\
\hline Age, years & & & 0.469 & 0.507 & & & 3.050 & 0.105 \\
\hline$<60$ & 55 & 50 & & & 24 & 81 & & \\
\hline$\geq 60$ & 70 & 53 & & & 41 & 82 & & \\
\hline Sex & & & 0.534 & 0.465 & & & 0.941 & 0.352 \\
\hline Male & 87 & 67 & & & 47 & 107 & & \\
\hline Female & 38 & 36 & & & 18 & 56 & & \\
\hline Tumor size, $\mathrm{cm}^{3}$ & & & 0.408 & 0.523 & & & 0.165 & 0.767 \\
\hline$<3$ & 55 & 41 & & & 26 & 70 & & \\
\hline$\geq 3$ & 70 & 62 & & & 39 & 93 & & \\
\hline Histological differentiation & & & 8.353 & 0.005 & & & 4.660 & 0.040 \\
\hline $\mathrm{I} / \mathrm{II}$ & 75 & 42 & & & 26 & 91 & & \\
\hline III/IV & 50 & 61 & & & 39 & 72 & & \\
\hline TNM stage & & & 8.289 & 0.005 & & & 15.317 & $<0.0001$ \\
\hline $\mathrm{I} / \mathrm{II}$ & 65 & 34 & & & 15 & 84 & & \\
\hline III/IV & 60 & 69 & & & 50 & 79 & & \\
\hline Lauren type & & & 4.080 & 0.046 & & & 5.635 & 0.018 \\
\hline Intestinal & 75 & 48 & & & 27 & 96 & & \\
\hline Diffuse & 50 & 55 & & & 38 & 67 & & \\
\hline Lymphatic metastasis & & & 26.784 & $<0.0001$ & & & 11.018 & 0.001 \\
\hline Positive & 65 & 87 & & & 54 & 98 & & \\
\hline Negative & 60 & 16 & & & 11 & 65 & & \\
\hline Distant metastasis & & & 6.981 & 0.008 & & & 5.553 & 0.018 \\
\hline Positive & 37 & 48 & & & 32 & 53 & & \\
\hline Negative & 88 & 55 & & & 33 & 110 & & \\
\hline Metastasis and recurrence & & & 11.255 & 0.001 & & & 17.137 & $<0.0001$ \\
\hline Positive & 45 & 60 & & & 44 & 61 & & \\
\hline Negative & 80 & 43 & & & 21 & 102 & & \\
\hline HER2 & & & 6.826 & 0.032 & & & 10.320 & 0.005 \\
\hline $0 / 1+$ & 110 & 77 & & & 45 & 142 & & \\
\hline $2+$ & 9 & 17 & & & 12 & 14 & & \\
\hline $3+$ & 6 & 9 & & & 8 & 7 & & \\
\hline
\end{tabular}

NDRG1, N-myc downstream regulated gene 1; VM, vasculogenic mimicry; TNM, Tumor-Node-Metastasis; HER2, human epidermal growth factor 2

$37^{\circ} \mathrm{C}$. Finally, all sections were counterstained with hematoxylin in $37^{\circ} \mathrm{C}$ for $2 \mathrm{~min}$, dehydrated by increasing gradient of ethanol (80-100\%) and mounted on coverslisps with Neutral gum. All GC sections were classified as intestinal type or diffuse type using the Alcian blue-periodic acid-Schiff method (16).

VM channel quantification. The characteristics of VM were assessed according to whether: The wall of VM vessels was lined with GC cells; red cells could be observed in the VM tube; or the GC cells in the VM wall were CD34- and $\mathrm{PAS}^{+}$ based on CD34/PAS double staining (17). VM channels in immunohistochemistry stained sections were counted under light microscope (magnification, $\mathrm{x} 400$ ). In total, 5 fields were randomly selected, and the average channel was defined as the number of VM vessels in one section.

Database and analysis. The data of 442 patients with GC were collected from The Cancer Genome Atlas (TCGA) (cancergenome.nih.gov). The overall gene expression in patients with GC was analyzed using weighted gene co-expression network analysis (WGCNA) (18). A functional enrichment analysis of NDRG1 was performed using Metascape ((http://metascape. org/) and the Gene Set Enrichment Analysis (GSEA) (software. broadinstitute.org/gsea/login.jsp) on the data from 415 patients 
Table III.Association between NDRG1 and the EMT-associated proteins.

\begin{tabular}{lcccc}
\hline Variable & $\begin{array}{c}\text { NDRG1 } \\
(\mathrm{n}=125)\end{array}$ & $\begin{array}{c}\text { Non-NDRG1 } \\
(\mathrm{n}=103)\end{array}$ & $\chi^{2}$ & P-value \\
\hline VM & & & 8.068 & 0.005 \\
Positive & 26 & 39 & & \\
Negative & 99 & 64 & & \\
VE-cadherin & & & 4.803 & 0.036 \\
Positive & 36 & 44 & & \\
Negative & 89 & 59 & & \\
Twist1 & & & 6.739 & 0.011 \\
Positive & 43 & 53 & & \\
Negative & 82 & 50 & & \\
Snail & & & 8.419 & 0.004 \\
Positive & 65 & 73 & & \\
Negative & 60 & 30 & & \\
E-cadherin & & & 5.080 & 0.029 \\
Positive & 85 & 55 & & \\
Negative & 40 & 48 & & \\
Vimentin & & & 4.485 & 0.042 \\
Positive & 30 & 38 & & \\
Negative & 95 & 65 & & \\
HER2 & & & 6.826 & 0.032 \\
0/1+ & 110 & 77 & & \\
$2+$ & 9 & 17 & & \\
$3+$ & 6 & 9 & & \\
\hline+ & & & & \\
\hline
\end{tabular}

NDRG1, N-myc downstream regulated gene 1; EMT, epithelial-mesenchymal transition; VE-cadherin, vascular endothelial-cadherin; E-cadherin, epithelial-cadherin; HER2, human epidermal growth factor 2 .

with GC (19). GraphPad Prism version 6 (GraphPad Software, Inc.) was used to present the data. The function of NDRG1 was analyzed using the ClueGO plug-in application in Cytoscape 2.8.3 (https://cytoscape.org). Kyoto Encyclopedia of Genes and Genomes (https://www.genome.jp/kegg/) pathway enrichment analysis was carried out and visualized using ClueGO and CluePedia with $\mathrm{P}<0.05$ as the cut-off value.

Statistical analysis. The data were analyzed using SPSS (version 16.0; SPSS, Inc., Chicago, IL, USA). P $<0.05$ was considered to indicate a statistically significant difference. Two-tailed Student's test was used for comparison of 'VM count' in two independent groups. 'VM count' in different HER2 group was analyzed using ANOVA test followed by Student-Newman-Keuls post-hoc test. The association between two proteins expression or VM formation and the clinicopathologic parameters was analyzed using two-tailed $\chi^{2}$ test. The correlation analysis was performed using Pearson's correlation or Spearman's correlation. Hazard and survival analysis were calculated using the Kaplan-Meier method, the log-rank method and multivariate Cox regression analysis.

\section{Results}

Correlation between NDRG1,VM and clinicopathological factors. To identify any correlations between NDRG1 and VM in patients with GC, a total of 228 GC specimens from the Tianjin Medical University Cancer Institute and Hospital were studied via immunohistochemistry and CD34/PAS double staining. Furthermore, NDRG1, VM and clinicopathological parameters were analyzed to identify any associations. The clinicopathological parameters of GC specimens are presented in Table I. In the GC specimens, tube cavities lined with $\mathrm{PAS}^{+}$, CD34- GC cells and red blood cells within the cavities were confirmed as VM channels (Fig. 1A). In total, 65 (28.51\%) samples with VM were identified among the $228 \mathrm{GC}$ specimens. Channels positive for PAS and CD34 were defined as endothelium-dependent blood vessels (EDVs) (Fig. 1A). The clinicopathological data of patients with GC with NDRG1 or VM were compared with data of those without NDRG1 or VM formation (Table II). Notably, the results from the present study demonstrated that NDRG1 expression and VM were correlated with tumor histological differentiation, Tumor-Node-Metastasis (TNM) stage (20), Lauren type, lymph node metastasis, distant metastasis, recurrence and metastasis, and HER2 expression in GC ( $\mathrm{P}<0.05$; Table II).

Among the GC specimens, 125 (54.82\%) samples were positive for NDRG1 expression (Table II and Fig. 1A). In NDRG1-positive cases, 26 patients were identified as VM-positive, and the VM formation rate was $20.80 \%$ (26/125). In the NDRG1-negative cases, 39 patients were identified as VM-positive, and the VM-positive rate was $37.86 \%$ (39/103). The overall correlation patterns of genes across GC samples within TCGA was analyzed using WGCNA (Fig. 1B). The VM formation rates in NDRG1-negative and NDRG1-positive patients were significantly different $\left(\chi^{2}=8.068 ; \mathrm{P}=0.005\right.$; Fig. $1 \mathrm{C}$ and D and Table III). The median value of the VM count in NDRG1-negative and NDRG1-positive samples was significantly different (Fig. 1E). The formation rate of VM in NDRG1-negative patients was higher than that in NDRG1-positive patients. Furthermore, NDRG1 expression and VM quantification were negatively correlated based on Pearson's correlation ( $\mathrm{r}=-0.141 ; \mathrm{P}<0.05$, Fig. 1F). NDRG1 expression and VE-cadherin expression were negatively correlated based on Pearson's correlation ( $r=-0.131 ; \mathrm{P}<0.05$, Fig. 1G).

HER2 expression was rated 0/1+ in $187(83.77 \%)$ patients, $2+$ in $26(10.09 \%)$ patients and $3+$ in $15(6.14 \%)$ patients (Table II). The expressions of HER2 are presented in Fig. 1H. In the HER2 0/1+ group, VM-positivity was identified in 45 cases (24.1\%); in the HER2 2+ group, VM-positivity was identified in 12 cases (46.2\%); and in the HER2 3+ group, VM-positivity was identified in 8 cases (53.3\%). There were considerable differences among the HER2 0/1+, HER2 2+ and HER $23+$ groups $\left(\chi^{2}=10.320 ; \mathrm{P}=0.005\right.$, Table II and Fig. 1I). The HER2 2+ and HER2 3+ groups demonstrated greater VM-positive rates than the HER2 $0 / 1+$ group $\left(\mathrm{P}=0.017, \chi^{2}=5.683\right.$ and $\mathrm{P}=0.013, \chi^{2}=6.147$, respectively). The combination HER2 $2+$ and HER2 $3+$ cases demonstrated a greater VM-positive rate than the HER2 $0 / 1+$ cases $(\mathrm{P}=0.002$, $\left.\chi^{2}=10.079\right)$. The median VM counts in the HER2 0/1+, HER2 2+ and HER2 3+ groups were significantly different 
Table IV. Univariate and multivariate Cox regression analysis of variables associated with gastric cancer mortality.

\begin{tabular}{|c|c|c|c|c|c|c|}
\hline \multirow[b]{2}{*}{ Variable } & \multicolumn{3}{|c|}{ Univariate analysis } & \multicolumn{3}{|c|}{ Mutlivariate analysis } \\
\hline & HR & $95 \% \mathrm{CI}$ & P-value & HR & $95 \% \mathrm{CI}$ & P-value \\
\hline Age, years & 1.008 & $0.992-1.024$ & 0.306 & & & \\
\hline Sex, male $=1$ & 0.837 & $0.582-1.203$ & 0.336 & & & \\
\hline VM, positive =1 & 1.672 & $1.170-2.389$ & 0.005 & & & \\
\hline NDRG1, positive $=1$ & 0.659 & $0.467-0.929$ & 0.017 & 0.660 & $0.462-0.941$ & 0.022 \\
\hline HER2, positive=1 & 1.516 & $1.138-2.021$ & 0.004 & 1.365 & $1.017-1.832$ & 0.038 \\
\hline Tumor size, $\geq 3 \mathrm{~cm}^{3}=1$ & 1.967 & $1.357-2.852$ & $<0.001$ & & & \\
\hline Lauren type, diffuse $=1$ & 1.396 & $0.990-1.969$ & 0.057 & & & \\
\hline TNM stage, III/IV=1 & 2.600 & $1.786-3.784$ & $<0.001$ & & & \\
\hline Histological differentiation, $\mathrm{I} / \mathrm{II}=1$ & 0.599 & $0.423-0.846$ & 0.004 & & & \\
\hline Lymphatic metastasis, positive $=1$ & 2.750 & $1.814-4.171$ & $<0.001$ & & & \\
\hline Distant metastasis, positive $=1$ & 2.980 & $2.095-4.240$ & $<0.001$ & & & \\
\hline Metastasis and recurrence, positive $=1$ & 5.326 & 3.568-7.949 & $<0.001$ & 4.186 & $2.421-7.238$ & $<0.001$ \\
\hline
\end{tabular}

HR, hazard ratio; CI, confidence interval; VM, vasculogenic mimicry; NDRG1, N-myc downstream regulated gene 1; HER2, human epidermal growth factor 2; TNM, Tumor-Node-Metastasis.

(Fig. 1J). Furthermore, HER2 expression and VM quantification was positively correlated based on Spearman's correlation $(\mathrm{r}=0.153 ; \mathrm{P}=0.021)$. Taken together, these results of the present study indicate that NDRG1 expression may weaken VM formation and that HER2 may promote VM formation.

Expression of NDRG1 is an indicator of good prognosis in patients with GC. To evaluate the association between hazard ratio and survival rate, Kaplan-Meier and multivariate Cox regression analyses were performed. Using univariate Cox proportional hazards regression analysis, pathological variables with VM, HER2, tumor size, TNM stage, lymphatic metastasis, distant metastasis and metastasis and recurrence were all identified to be significant predictors of prognosis in patients with GC. When using the multivariate Cox analysis only, HER2 and metastasis and recurrence were significant independent risk factors in patients with GC, with hazard ratios of 1.365 and 4.186, respectively. NDRG1 was the most favorable factor in patients with GC with a hazard ratio of 0.66 (Table IV).

A univariate survival analysis was performed using a Kaplan-Meier survival analysis and the log-rank method. The correlations between VM, NDRG1 protein expression, HER2 expression and the survival rate of patients with GC following surgical procedures [rate of follow-up, 97.81\% (223/228)] were investigated. Follow up was performed for all patients by clinic interview or phone call. By the end of the follow-up time in January 2014, 5 patients or their family could not be contacted and were therefore lost. Overall, 5 patients were lost during follow-up. The cumulative survival function in patients with GC is presented in Fig. 2A. Patients without VM had a significantly longer survival time compared with those with VM (log-rank test, $\chi^{2}=8.413 ; \mathrm{P}=0.004$; Fig. 2B). Patients with high NDRG1 expression levels had significantly longer survival time compared with those with low NDRG1 expression levels (log-rank test, $\chi^{2}=5.925 ; \mathrm{P}=0.015 ;$ Fig. $2 \mathrm{C}$ ). Patients with HER2
$3+$ expression levels had a significantly shorter survival time compared with those with HER2 2+ and HER2 0/1+ expression levels (log-rank test, $\chi^{2}=14.656 ; \mathrm{P}=0.001$; Fig. 2D). The results of the present study revealed that the overall survival time was significantly lower in patients with HER2 3+ and NDRG1-negative tumors compared with those with HER2 $0 / 1+$ and NDRG1-positive tumors (log-rank test, $\chi^{2}=25.96$; $\mathrm{P}<0.0001$; Fig. 2E). The overall survival time was significantly lower in patients with VM-positive and NDRG1-negative samples compared with those with VM-negative and NDRG1-positive samples (log rank test, $\chi^{2}=14.058 ; \mathrm{P}=0.001$; Fig. 2F). Therefore, the results from the present study indicate that NDRG1 has a negative association with the prognosis of patients with GC and HER2 has a positive association with the prognosis of patients with GC.

NDRG1 protein may weaken VM formation in patients with GC by decreasing EMT-associated markers and HER 2 expression. To further clarify the role of NDRG1 in the decrease in VM formation, the expression levels of VM-associated markers (VE-cadherin), EMT-associated markers (Twist1, Snail, E-cadherin and vimentin) and HER2 were detected via immunohistochemistry.

In the NDRG1-positive group, VE-cadherin expression was positive in $45.00 \%$ (36/80), Twist1 expression was positive in $44.79 \%$ (43/96), Snail expression was positive in $47.10 \%$ $(65 / 138)$, E-cadherin expression was positive in $60.71 \%(85 / 140)$ and vimentin expression was positive in $44.12 \%(30 / 68)$ of cases. In the NDRG1-negative group, VE-cadherin expression was positive in $55 \%$ (44/80), Twist1 expression was positive in $55.21 \%$ (53/96), Snail expression was positive in $52.90 \%$ (73/138), E-cadherin expression was positive in $39.29 \%(55 / 140)$ and vimentin expression was positive in $55.88 \%(38 / 68)$ of cases. The expression of VE-cadherin and EMT-associated markers in the NDRG1-negative and NDRG1-positive groups was significantly different (Table III; Fig. 3B). These results 
A
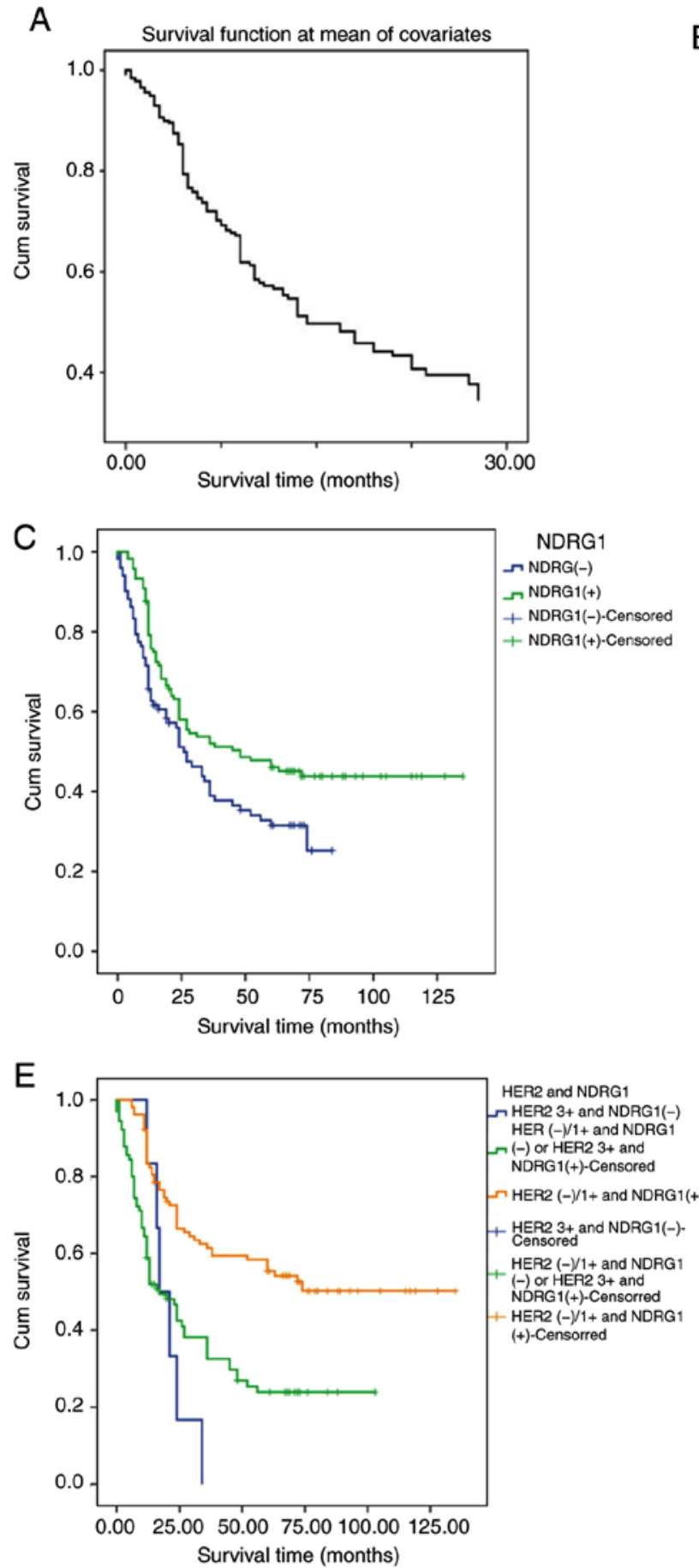

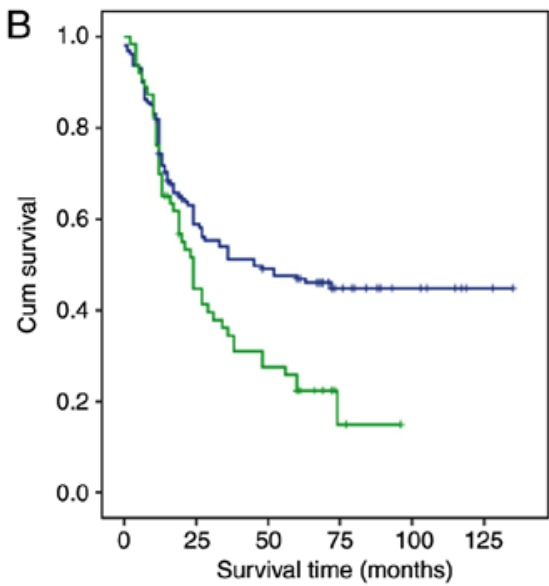

$\begin{aligned} & \text { VM } \\ & \sim \text { VM (-) } \\ &- \text { VM (+) } \\ &+(-) \text {-Censored } \\ &+(+)+\text { Censored }\end{aligned}$
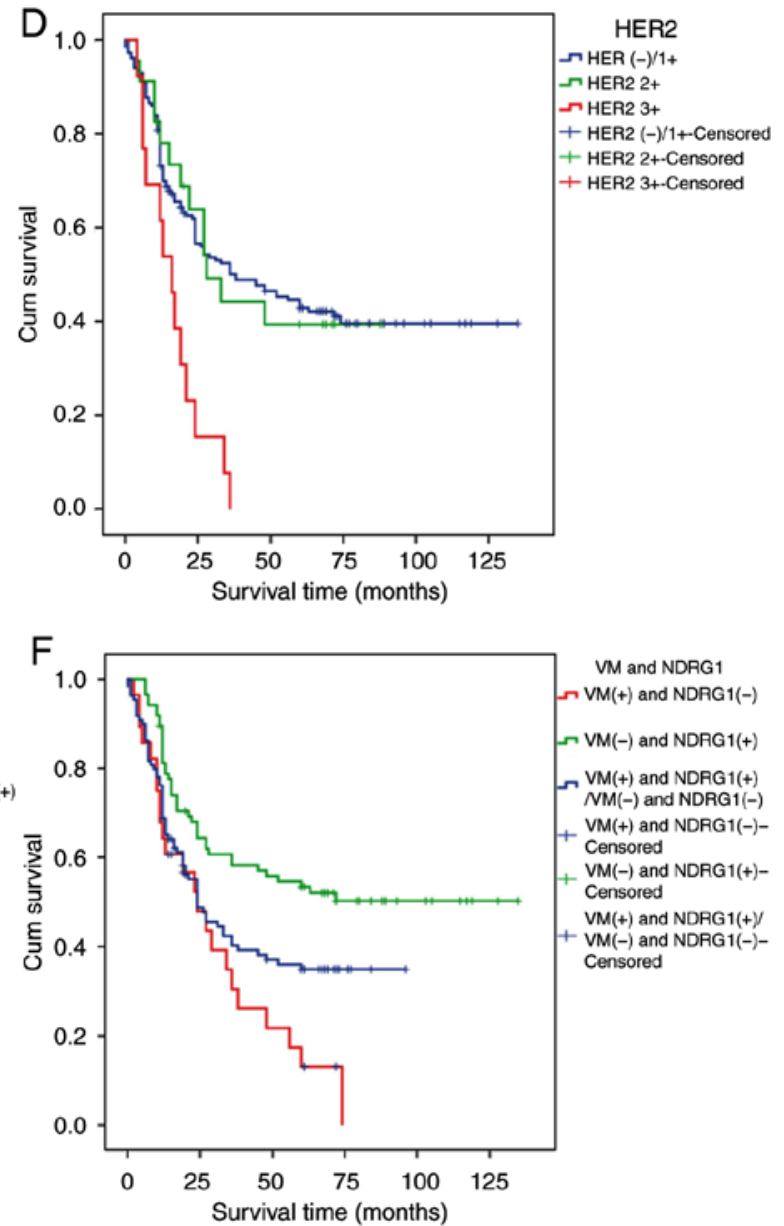

Figure 2. Cumulative survival function and Kaplan-Meier survival curve. (A) The cumulative survival function in patients with GC. (B) VM expression is associated with a poor prognosis. (C) NDRG1 expression is associated with a good prognosis. (D) HER2 expression is associated with a poor prognosis. (E) A combination of NDRG1- and HER2 3+ expression is associated with a poor prognosis. (F) A combination of NDRG1-positive and VM-negative expression was associated with a good prognosis. GC, gastric carcinoma; HER2, human epidermal growth factor receptor 2; NDRG1, N-myc downstream regulated gene 1; VM, vasculogenic mimicry.

suggest that NDRG1 suppresses the expression of Twist1, Snail, VE-cadherin and vimentin, whereas NDRG1 enhances the expression of E-cadherin $(\mathrm{P}<0.05)$.

In addition, the functional enrichment analysis of NDRG1 in 415 cases of GC from TCGA database was performed using Metascape and GSEA. All 442 cases of GC within TCGA database are presented in Table V.

The Metascape analysis revealed that 242 genes exhibited significantly increased expression $(\mathrm{P}<0.05$; Fig. 4A), and 239 genes exhibited significantly decreased expression in the 211 samples with high NDRG1 expression $(\mathrm{P}<0.05$; Fig. 4B). The GSEA analysis indicated that 47 pathways were significantly upregulated ( $\mathrm{P}<0.05$; Fig. $4 \mathrm{C})$ and 46 pathways were significantly downregulated in the 211 samples with high NDRG1 expression $(\mathrm{P}<0.05$; Fig. 4D). P-values were automatically generated by the Cytoscape software.

Compared with the two groups with high and low NDRG1 expression, the differentially expressed genes were focused 


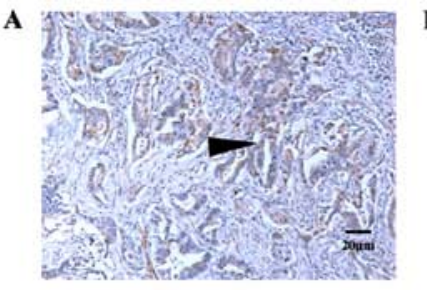

VE-cadherin (x200)

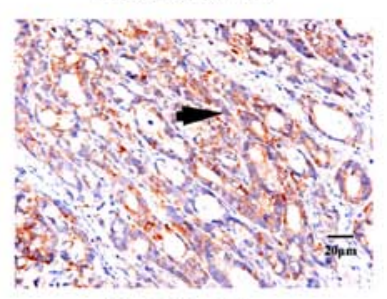

Twist 1 (x200)

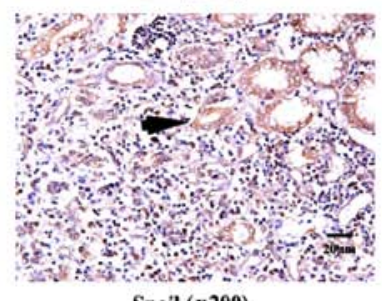

Snail (x200)
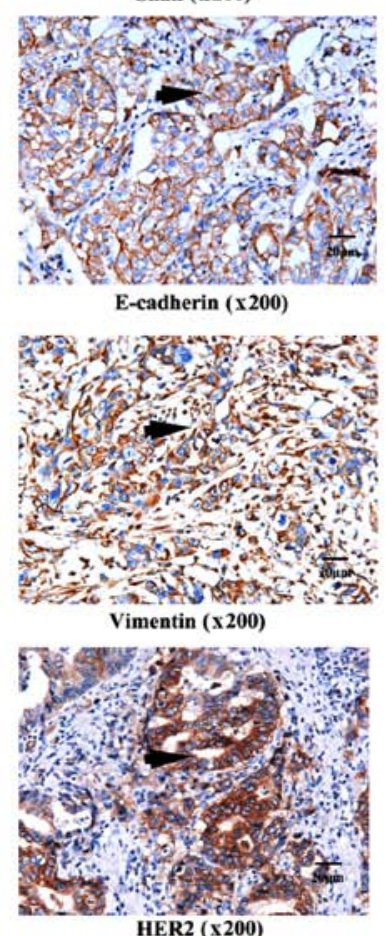
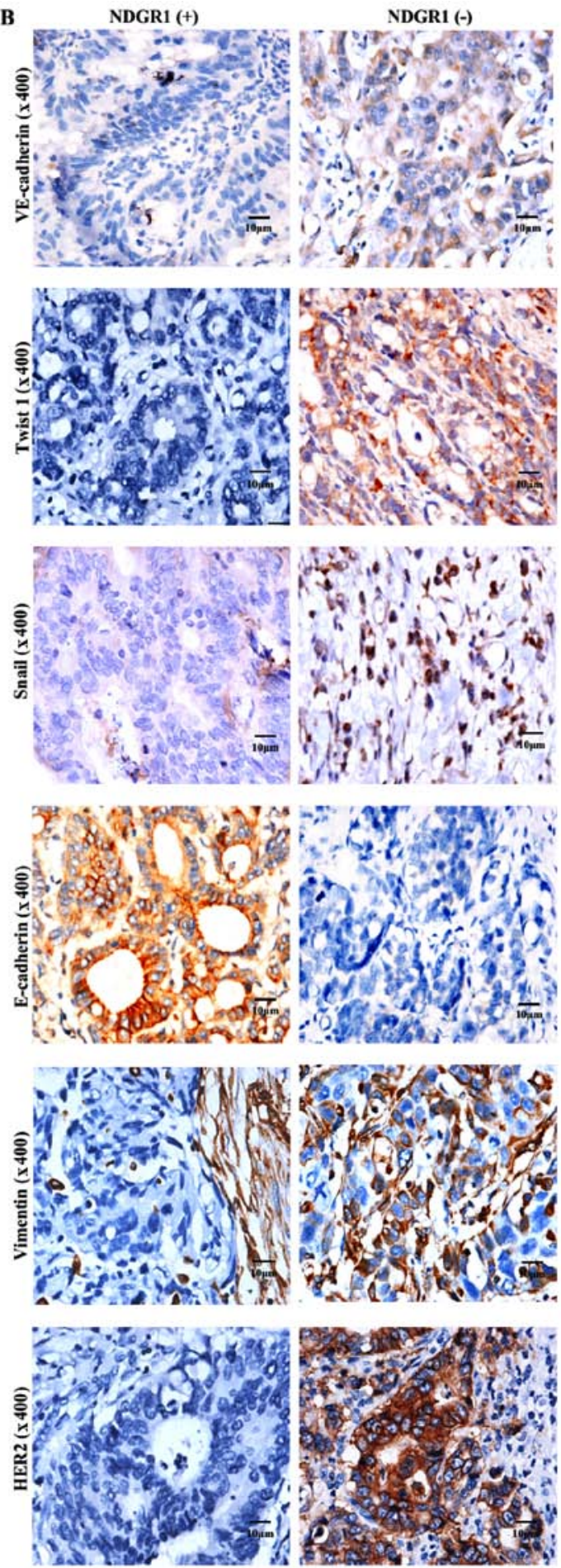
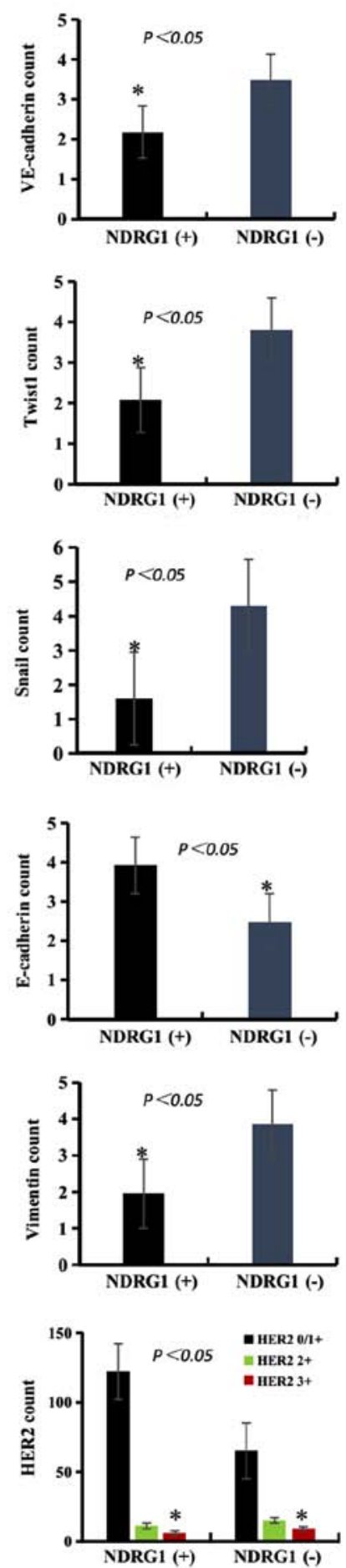

Figure 3. IHC staining of VE-cadherin, EMT-associated markers (Twist1, Snail, E-cadherin and vimentin) and HER2 in GC samples. (A) IHC staining of VE-cadherin, Twist1, Snail, E-cadherin and vimentin in GC samples. The brown particles were present in the cytoplasm (VE-cadherin, Twist1, Snail and vimentin) or membrane (VE-cadherin, E-cadherin and HER2) or nucleus (Snail) of GC cells (black arrow). Scale bar, $20 \mu \mathrm{m}$. Magnification, x200. (B) IHC staining of VE-cadherin, Twist1, Snail, E-cadherin, Vimentin and HER2 expression in NDRG1-positive (left images) and NDRG1-negative (right images) samples. The positive rate of VE-cadherin, Twist1, Snail, vimentin and HER2 in NDRG1-positive were lower than that in NDRG1-negative. The positive rate of E-cadherin in NDRG1-positive were higher than that in NDRG1-negative. Scale bar, $10 \mu \mathrm{m}$. Magnification, $\mathrm{x} 400$. "P<0.05. IHC, immunohistochemistry; VE-cadherin, vascular endothelial-cadherin; E-cadherin, epithelial-cadherin; EMT, epithelial mesenchymal transition; HER2, human epidermal growth factor 2; GC, gastric carcinoma; NDRG1, N-myc downstream regulated gene 1.

primarily on the pathways of development and differentiation of epithelial cells. The results of the present study indicate that NDRG1 serves an important role in maintaining the epithelial phenotype of GC, and VM occurs more easily in GC with low NDRG1 expression.
In addition, correlations between NDRG1 and EMT-associated factors were investigated from two aspects. On the one hand, in cases of GC from TCGA database, the results indicated that NDRG1 and CDH1 (E-cadherin) were positively correlated in HER2-normal and HER2-amplified samples, and 
Table V. Clinical data of gastric carcinoma in The Cancer Genome Atlas.

\begin{tabular}{|c|c|c|c|c|}
\hline Characteristic & Alive, $(n=369)$ & Deceased, tumor present, $(n=58)$ & Deceased, no tumor, $(n=15)$ & Total, $(n=442)$ \\
\hline \multicolumn{5}{|l|}{ Sex, n $(\%)$} \\
\hline Female & $138(37.4)$ & $16(27.6)$ & $4(27.0)$ & $158(36.0)$ \\
\hline Male & $231(63.0)$ & $42(72.4)$ & $11(73.3)$ & $284(64.3)$ \\
\hline \multicolumn{5}{|l|}{ Age, years } \\
\hline Mean $( \pm \mathrm{SD})$ & $65.4(10.8)$ & $64.6(10.1)$ & $73.3(9.5)$ & $65.3(10.5)$ \\
\hline Median (range) & $67(30-90)$ & $66(41-86)$ & $73(47-90)$ & $66(34-90)$ \\
\hline \multicolumn{5}{|l|}{ Stage, n (\%) } \\
\hline I & $3(0.8)$ & & & $3(0.7)$ \\
\hline IA & $13(3.5)$ & & $2(13.3)$ & $14(3.2)$ \\
\hline IB & $35(9.5 \%)$ & $5(8.6)$ & $3(20.0)$ & $38(8.6)$ \\
\hline II & $32(8.7)$ & $2(3.4)$ & & $29(6.6)$ \\
\hline IIA & $38(10.3)$ & $1(1.7)$ & $1(6.7)$ & $38(8.6)$ \\
\hline IIB & $55(15.0)$ & $1(1.7)$ & $1(6.7)$ & $55(12.4)$ \\
\hline III & $2(0.5)$ & $1(1.7)$ & & $2(0.5)$ \\
\hline IIIA & $63(17.1)$ & $11(19.0)$ & $3(20.0)$ & $68(15.4)$ \\
\hline IIIB & $49(13.3)$ & $11(19.0)$ & $3(20.0)$ & $62(14.0)$ \\
\hline IIIC & $32(8.7)$ & $6(10.3)$ & $1(6.7)$ & $38(8.6)$ \\
\hline IV & $24(6.5)$ & $17(29.3)$ & & $38(8.6)$ \\
\hline \multicolumn{5}{|l|}{ Grade, n (\%) } \\
\hline G1 & $12(3.3)$ & $1(1.7)$ & & $10(2.3)$ \\
\hline G2 & $129(35.0)$ & $24(41.4)$ & $6(40.0)$ & $138(31.2)$ \\
\hline G3 & 221 (59.9) & $31(53.4)$ & $9(60.0)$ & $240(54.3)$ \\
\hline GX & 7 (1.9) & $2(3.4)$ & & 7 (1.6) \\
\hline
\end{tabular}

$\mathrm{SD}$, standard deviation.

that NDRG1 and vimentin, and NDRG1 and fibronectin 1 were negatively correlated in HER2-amplified samples at the RNA level (Fig. 5A and B). On the other hand, correlations among NDRG1 and EMT-associated markers were determined using Pearson's correlation in patients with GC. The results revealed that NDRG1 has a negative correlation with Twist1, Snail and vimentin (Fig. 5C, D and E, respectively) and a positive correlation with E-cadherin at the protein level (Fig. 5F). These results suggest that NDRG1 may hinder EMT.

The results from IHC staining of VE-cadherin and EMT-associated factors (Twist1, Snail, E-cadherin and vimentin) in GC samples are presented in Fig. 3A. In the NDRG1-positive group, HER2 0/1+ expression was identified in $58.82 \%$ (110/187), HER2 2+ expression was identified in $34.62 \%$ (9/26) and HER2 3+ expression was identified in 40.00\% (6/15) of cases. In the NDRG1-negative group, HER2 0/1+ expression was identified in $41.18 \%$ (77/187), HER2 2+ expression was identified in $65.38 \%(17 / 26)$ and HER2 3+ expression was identified in $60 \%(9 / 15)$ of cases. There were significant differences in expression among the HER2 0/+, HER2 2+ and HER2 $3+$ groups $\left(\chi^{2}=6.826 ; \mathrm{P}=0.032\right.$; Table II, Fig. 3B). NDRG1 and HER2 expression was negatively correlated based on Spearman's correlation analysis $(\mathrm{r}=-0.149 ; \mathrm{P}=0.025)$. At the same time, the analytical data from TCGA indicated that NDRG1 expression was higher in HER2-amplified samples compared with HER2-normal samples at the RNA level. The results of the present study suggest that NDRG1 may decrease the expression of HER2 $(\mathrm{P}<0.05)$; the molecular mechanisms underlying this process require validation in the future.

Overall, the results of the present study indicate that NDRG1 may weaken VM formation through EMT- and HER2-mediated mechanisms.

\section{Discussion}

GC is characterized by a high growth rate, high malignancy, and high rates of recurrence and metastasis $(21,22)$. In the present study, the metastasis rate of 228 cases of GC was $46.05 \%$. The 5-year survival rate of 228 patients with GC was $30.71 \%$. It is critical to investigate the novel molecules and molecular mechanisms that are involved in the development of GC. It has been indicated that VM serves an important role in regulating the development of GC (4). In the present study, $28.5 \%$ of patients with GC were VM-positive. Patients with VM had a significantly poorer prognosis than those patients without VM.

NDRG1 has been revealed to serve a key role in physiological conditions, such as cellular differentiation and the cell cycle, and pathophysiological conditions, such as cancer pathology. NDRG1 inhibits tumor progression in the majority of cancer types; however, the inhibitory effect of NDRG1 is tissue specific, and the 


\section{A}
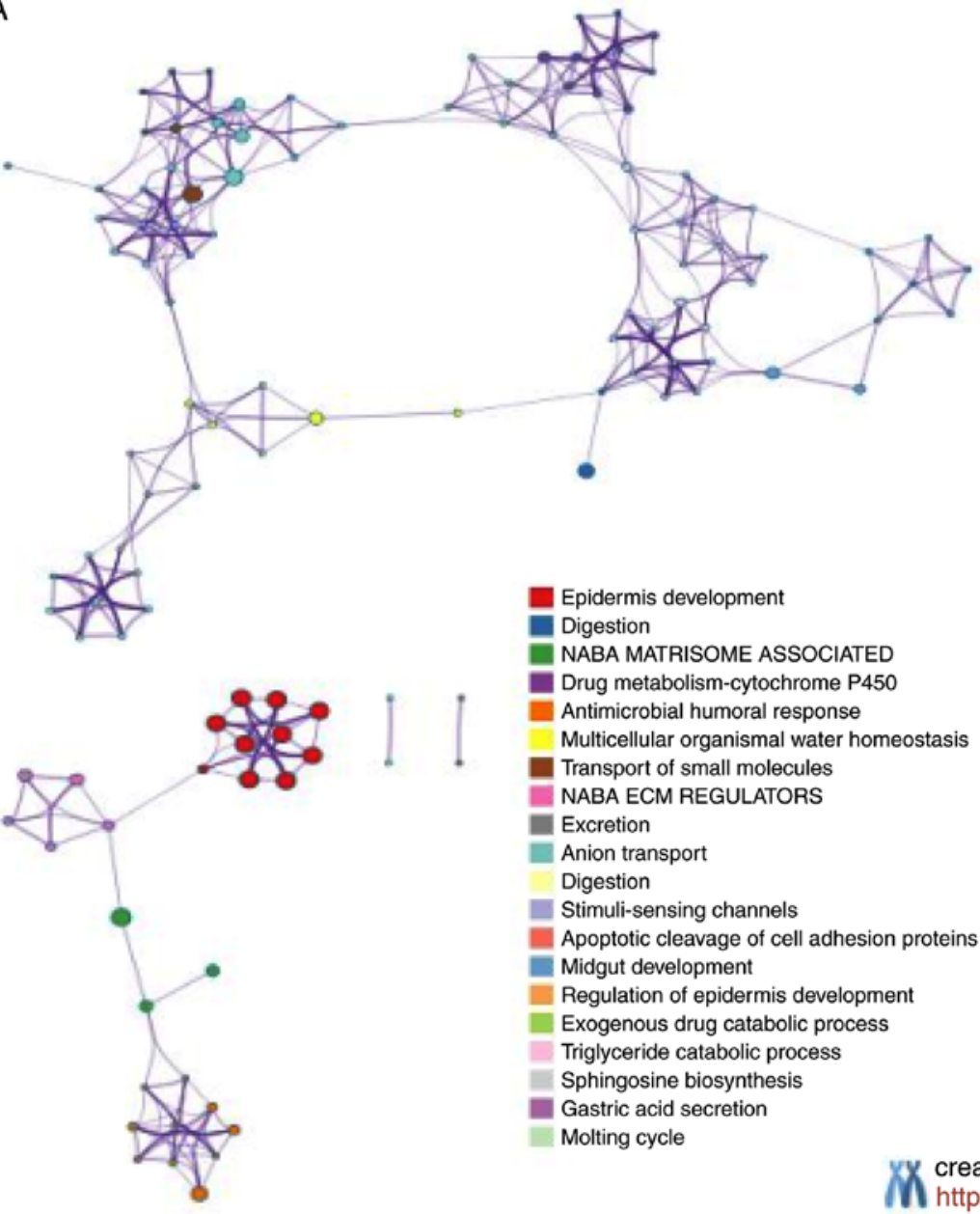

Digestion

NABA MATRISOME ASSOCIATED

Drug metabolism-cytochrome P450

- Antimicrobial humoral response

Multicellular organismal water homeostasis

Transport of small molecules

NABA ECM REGULATORS

Excretion

Anion transport

Digestion

Stimuli-sensing channels

Apoptotic cleavage of cell adhesion proteins

Midgut development

Regulation of epidermis development

Exogenous drug catabolic process

Triglyceride catabolic process

Sphingosine biosynthesis

Gastric acid secretion

Molting cycle

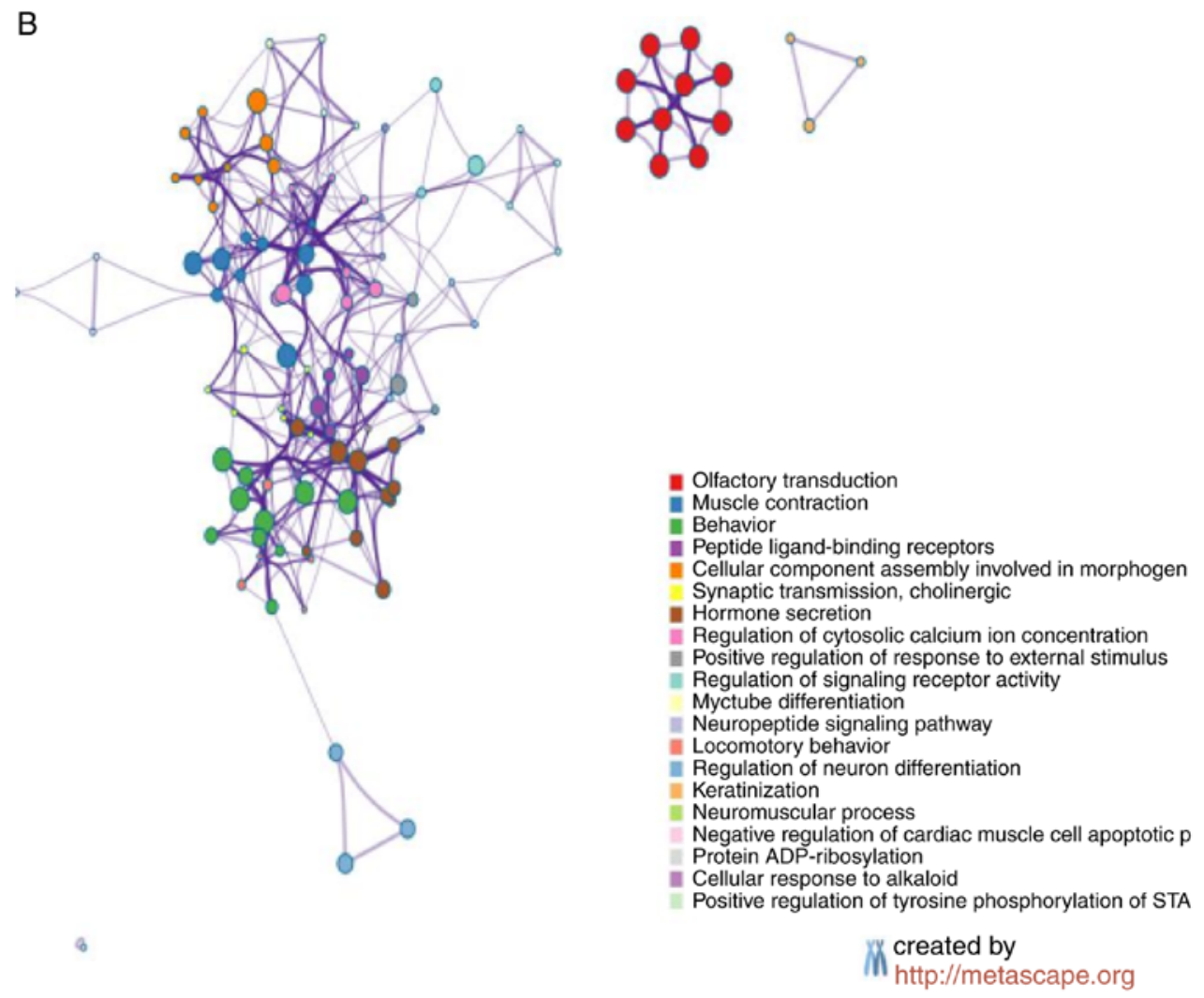

Figure 4. Functional enrichment analysis of NDRG1. (A) The principal pathways of upregulated genes were determined in the high NDRG1 expression population using Metascape analysis. (B) The principal pathways of downregulated genes were determined in the high NDRG1 expression population using Metascape analysis. 

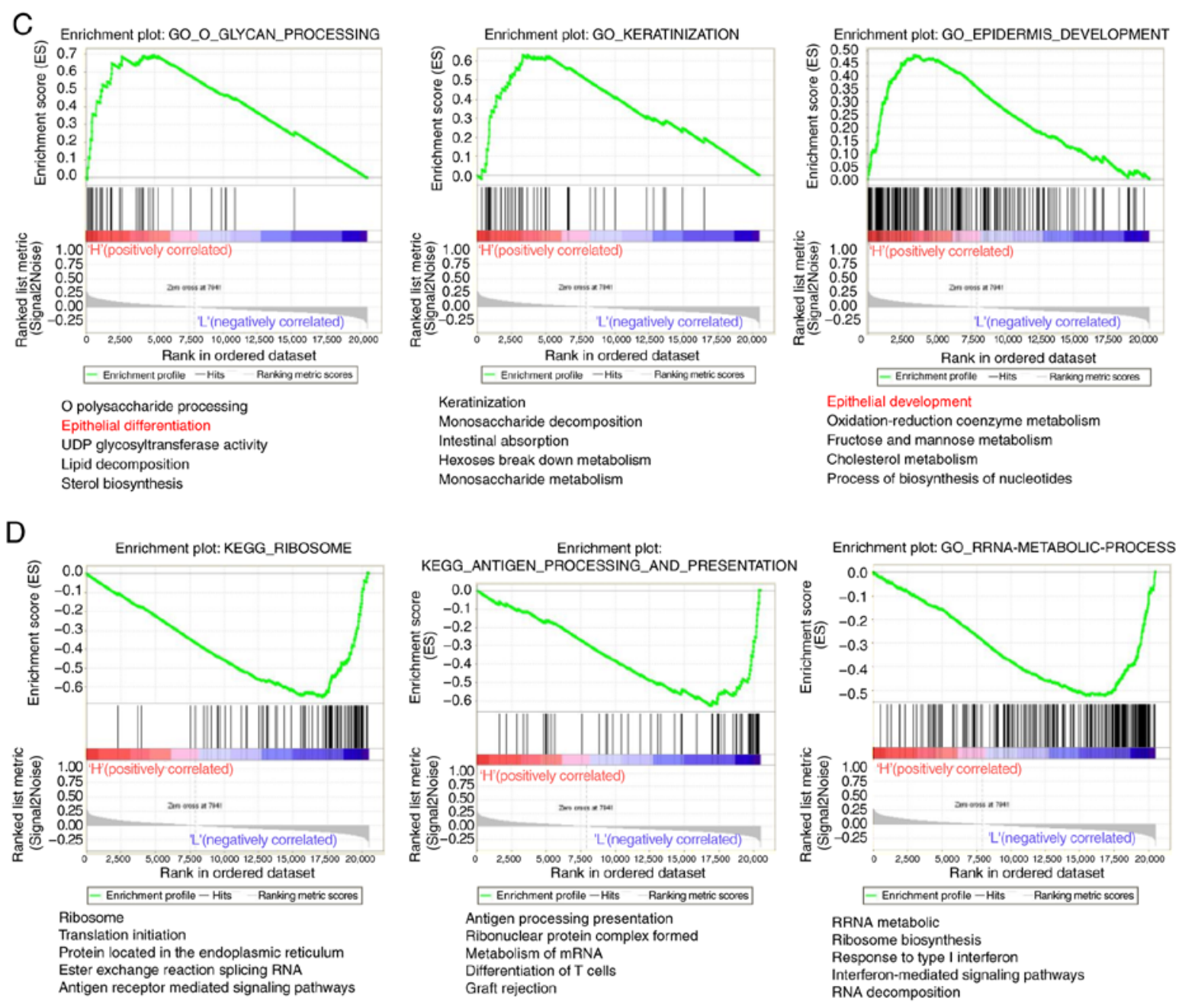

Figure 4. Continued. Functional enrichment analysis of NDRG1. (C) The genes differentially expressed in the high NDRG1 expression group were focused primarily on the pathways of development and differentiation of epithelial cells. (D) The genes differentially expressed between the low NDRG1 expression groups were mainly focused on the pathways of development and differentiation of epithelial cells. NDRG1, N-myc downstream regulated gene 1.

effects between tissues may be completely different. For example, NDRG1 has been identified as a metastasis suppressor gene in colon and prostate cancer, but the opposite results were demonstrated in hepatocellular carcinoma and breast cancer $(23,24)$. Results of the present study indicated that NDRG1 possesses inhibitory effects within patients with GC, which is consistent with the results of a previous study (2). Another study reported that NDRG1 promotes the metastasis of human scirrhous GC cells through EMT (25). Therefore, the inhibitory effects of NDRG1 in GC require verification in future studies.

Across the cohort of patients included in the present study, $54.8 \%$ of the patients with GC exhibited high NDRG1 protein expression. NDRG1 expression had a significant negative correlation with TNM stage, lymph node metastasis, distant metastasis, and recurrence and metastasis in GC. Furthermore, patients with high NDRG1 expression levels had a significantly lower VM-positive rate and longer survival. VM-positivity was present in 37.8\% of GC cases negative for NDRG1 expression. The expression of NDRG1 had a negative correlation with VM formation. VE-cadherin has been identified as a key marker for indicating the presence of VM, and tumor cells lacking VE-cadherin are incapable of forming VM tubes (26). The results from the present study revealed that the presence of
NDRG1 resulted in decreased expression of VE-cadherin, and that NDRG1 was negatively correlated with VE-cadherin. Therefore, NDRG1-mediated suppression of tumor metastasis in GC may occur through decreased VM formation.

To further clarify the suppressive effects of NDRG1 on VM formation, the levels of EMT-associated factors (Twist1, Snail, E-cadherin and vimentin) and HER2 were assessed. EMT has been proposed as a key process in cancer progression, whereby epithelial cells acquire mesenchymal properties and exhibit decreased cell-matrix adhesion. Notably, tumor cells may gain dedifferentiated phenotypes to convert onto endothelial cells via EMT, as revealed in our previous study (6). Twist1 and Snail are transcription factors that serve an important role in the EMT process, a process associated with cancer progression and VM formation $(6,27)$. The results of present study and the previous study (6), indicated that NDRG1 significantly enhanced the expression of the epithelial marker E-cadherin and decreased the expression of the mesenchymal marker vimentin in GC specimens. In addition, the results of the present study that were derived from Metascape and GSEA were consistent with the analysis of patients with GC. Furthermore, NDRG1 may decrease the expression of the transcription factors Twist1 and Snail in GC specimens. A similar conclusion was made by 
$\mathbf{A}$
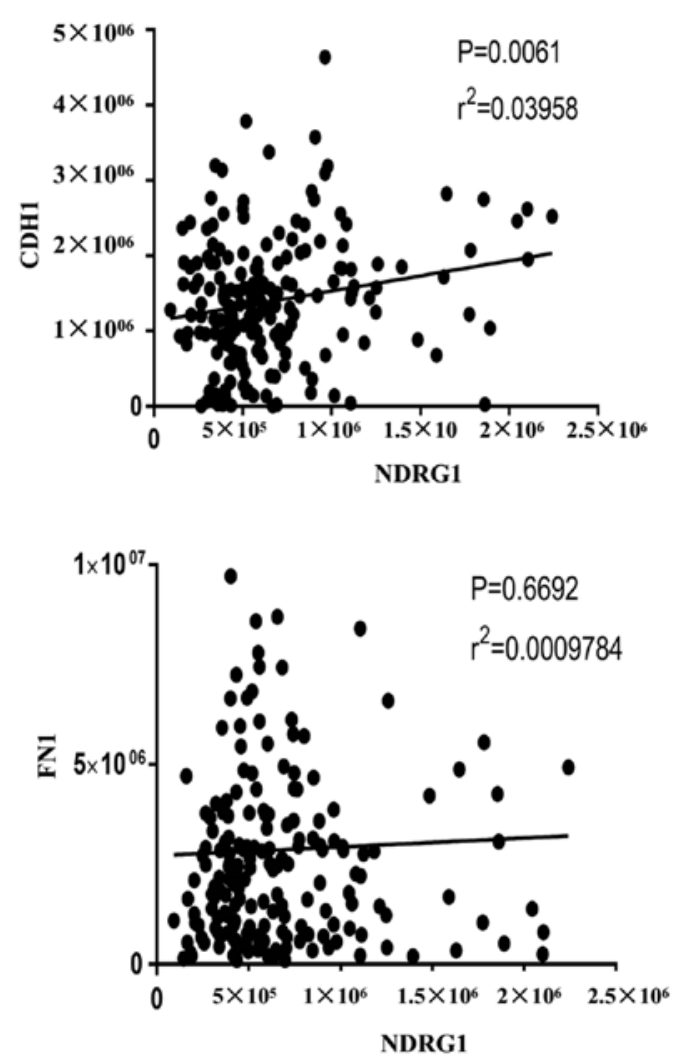

HER2-normal

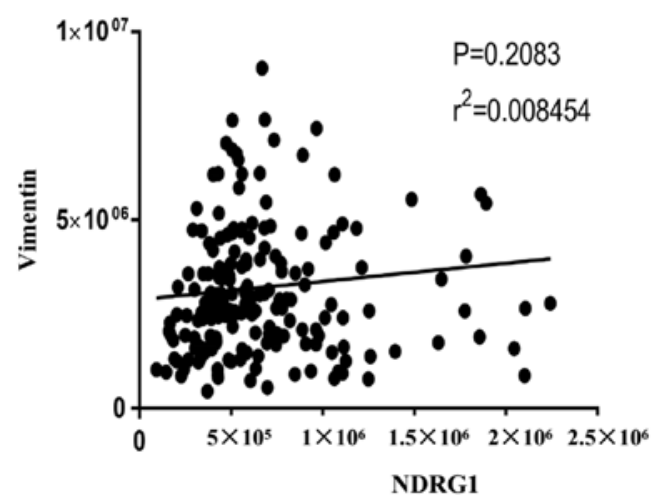

B

HER2-amplification
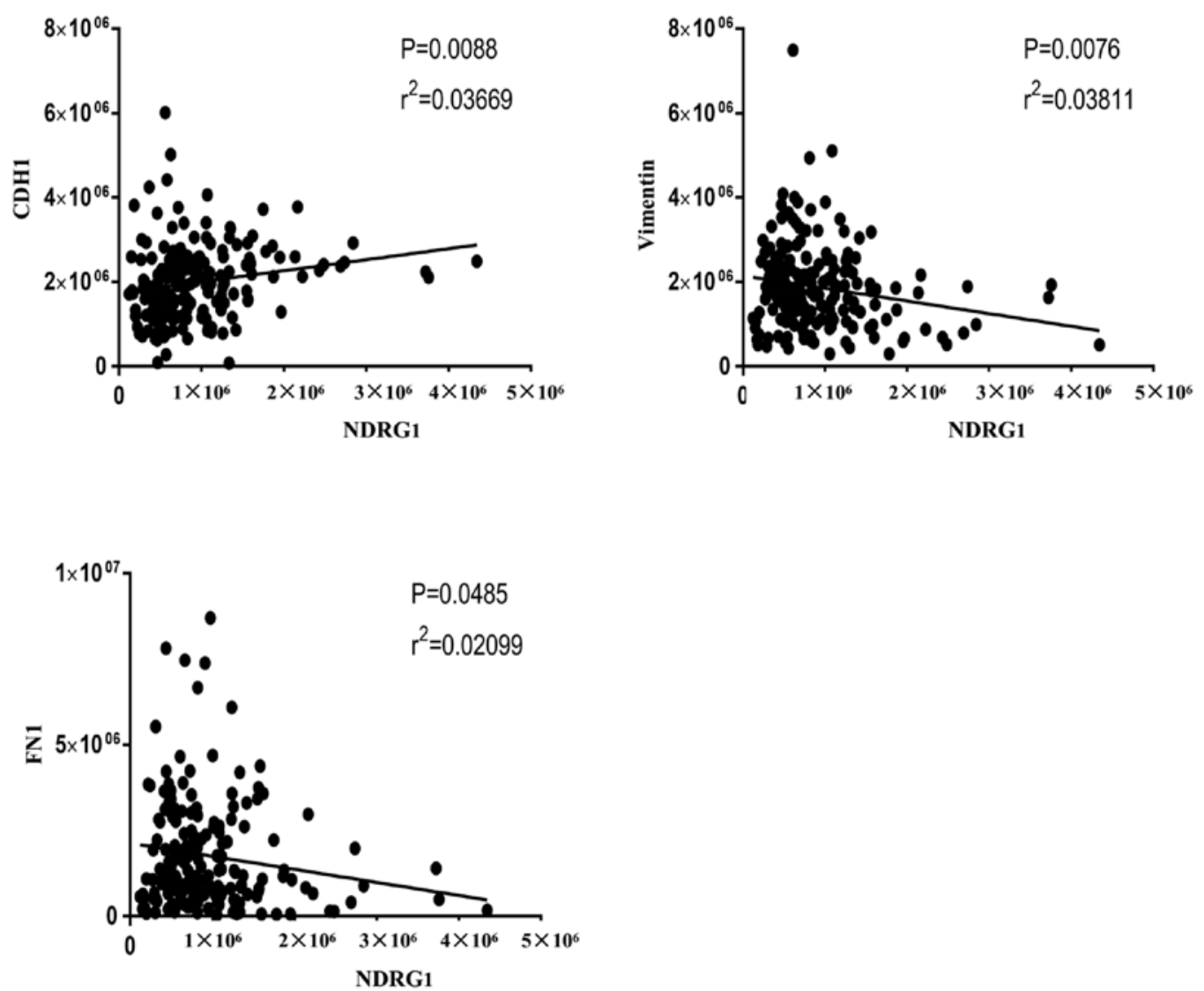

Figure 5. Correlations between NDRG1 and EMT-associated markers using Pearson's correlation. (A) NDRG1 and CDH1 were positively correlated in HER2-normal samples. Results were derived from TCGA database. (B) NDRG1 and CDH1 were positively correlated in HER2-amplified samples, and NDRG1 and vimentin, and NDRG1 and fibronectin 1 were negatively correlated in HER2-amplified samples. Results were derived from TCGA database. 

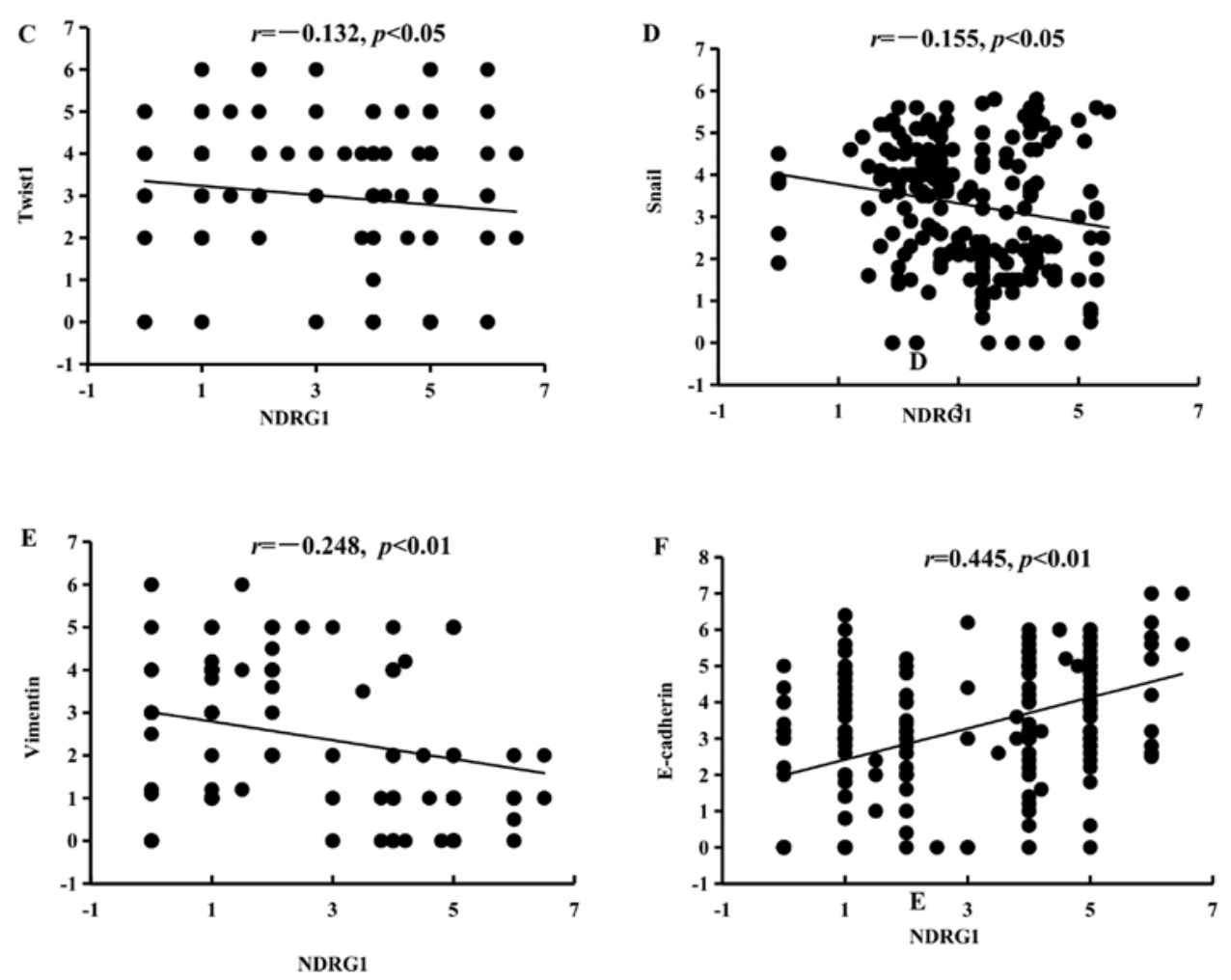

Figure 5. Continued. Correlations between NDRG1 and EMT-associated markers using Pearson's correlation. (C) NDRG1 and Twist1 were negatively correlated at the protein level. (D) NDRG1 and Snail were negatively correlated at the protein level. (E) NDRG1 and vimentin were negatively correlated at the protein level. (F) NDRG1 and E-cadherin were positively correlated at the protein level. NDRG1, N-myc downstream regulated gene 1; EMT, epithelial-mesenchymal transition; HER2, human epidermal growth factor receptor 2; E-cadherin, epithelial-cadherin; CDH1, E-cadherin; FN1, fibronectin 1.

Lee et al (27); thus, NDRG1 may suppress VM formation and metastasis in GC by inhibiting EMT.

The HER2 protein is a member of the epidermal growth factor receptor family. It has been demonstrated that HER2 overexpression is associated with a poor prognosis in patients with GC (28). In the present study, patients with GC with HER $23+$ expression had a worse prognosis compared with those with HER2 2+ and HER2 0/1+ expression, which is consistent with the results of a previous study (29). Currently, HER2 is regarded as an important and promising target in the treatment of HER2-positive patients with GC $(30,31)$. NDRG1 may downregulate the ErbB family of receptors to inhibit oncogenic signaling pathways in other types of tumor in humans (11). Preliminary research has indicated that HER2 overexpression induces VM formation through upregulation of VE-cadherin in invasive breast carcinoma (32). The results from the present study revealed that patients with GC with HER2 3+ expression had a higher VM formation rate compared with those with HER2 2+ and HER2 0/1+ expression. Furthermore, samples with higher expression of HER2 presented with a higher VM count, and NDRG1 decreased the HER2 expression levels. These results demonstrate that NDRG1 may suppress VM formation and metastasis in GC by decreasing HER2 expression.

It is reasonable to assume that NDRG1 may act as a protective agent against GC progression. The results of the present study indicate that NDRG1 may be a potentially important predictive biomarker of recurrence, metastasis and poor outcome for patients with GC, and may provide a basis for the development of targeted treatments for patients with
GC. However, the results of the present study were limited in human specimens and, as such, further studies are required in order to confirm these conclusions using mechanistic experiments in vitro.

\section{Acknowledgements}

Not applicable.

\section{Funding}

The present study was supported by The National Natural Science Foundation of China (grant no. 81572872), Key project of the National Natural Science Foundation of China (grant no. 81230050), and The Science \& Technology Development Fund of Tianjin Education Commission for Higher Education (grant no. 2018KJ074).

\section{Availability of data and materials}

The datasets used and/or analyzed during the present study are available from the corresponding author upon reasonable request.

\section{Authors' contributions}

$\mathrm{XD}$ and BS designed the study and wrote the manuscript. YH, HS, CC and XZ performed the experiments and analyzed data. All authors read and approved the final version of the manuscript. 


\section{Ethics approval and consent to participate}

This study was approved by the Ethics Committee of Tianjin Medical University. All patients provided written informed consent. The privacy rights of human subjects were maintained.

\section{Patient consent for publication}

Not applicable.

\section{Competing interests}

The authors declare that they have no competing interests.

\section{References}

1. Leung WK, Wu MS, Kakugawa Y, Kim JJ, Yeoh KG, Goh KL, Wu KC, Wu DC, Sollano J, Kachintorn U, et al: Screening for gastric cancer in Asia: Current evidence and practice. Lancet Oncol 9: 279-287, 2008

2. Chang X, Xu X, Ma J, Xue X, Li Z, Deng P, Zhang S, Zhi Y, Chen J and Dai D: NDRG1 expression is related to the progression and prognosis of gastric cancer patients through modulating proliferation, invasion and cell cycle of gastric cancer cells. Mol Biol Rep 41: 6215-6223, 2014.

3. McLemore MR: The role of the data safety monitoring board: Why was the Avastin phase III clinical trial stopped? Clin J Oncol Nurs 10: 153-154, 2006.

4. Qu B, Guo L, Ma JL and Lv Y: Antiangiogenesis therapy might have the unintended effect of promoting tumor metastasis by increasing an alternative circulatory system. Med Hypotheses 74: 360-361, 2010.

5. Maniotis AJ, Folberg R, Hess A, Seftor EA, Gardner LM, Pe'er J, Trent JM, Maniotis AJ, Folberg R, Hess A, et al: Vascular channel formation by human melanoma cells in vivo and in vitro: Vasculogenic mimicry. Am J Pathol 155: 739-752, 1999.

6. Sun T, Zhao N, Zhao XL, Gu Q, Zhang SW, Che N, Wang XH, Du J, Liu YX and Sun BC: Expression and functional significance of Twist1 in hepatocellular carcinoma: Its role in vasculogenic mimicry. Hepatology 51: 545-556, 2010.

7. Liu TJ, Sun BC, Zhao XL, Zhao XM, Sun T, Gu Q, Yao Z, Dong XY, Zhao N and Liu N: CD133+ cells with cancer stem cell characteristics associates with vasculogenic mimicry in triple-negative breast cancer. Oncogene 32: 544-553, 2013.

8. Du J, Sun B, Zhao X, Gu Q, Dong X, Mo J, Sun T, Wang J, Sun R and Liu Y: Hypoxia promotes vasculogenic mimicry formation by inducing epithelial-mesenchymal transition in ovarian carcinoma. Gynecol Oncol 133: 575-583, 2014.

9. Sun J, Sun B, Zhu D, Zhao X, Zhang Y, Dong X, Che N, Li J, Liu F, Zhao N, et al: HMGA2 regulates CD44 expression to promote gastric cancer cell motility and sphere formation. Am J Cancer Res 7: 260-274, 2017.

10. Richardson A, Kovacevic Z and Richardson DR: Iron chelation: Inhibition of key signaling pathways in the induction of the epithelial mesenchymal transition in pancreatic cancer and other tumors. Crit Rev Oncog 18: 409-434, 2013.

11. Kovacevic Z, Menezes SV, Sahni S, Kalinowski DS, Bae DH, Lane DJ and Richardson DR: The metastasis suppressor, N-MYC downstream-regulated gene-1 (NDRG1), down-regulates the ErbB family of receptors to inhibit downstream oncogenic signaling pathways. J Biol Chem 291: 1029-1052, 2016.

12. Sun T, Sun BC, Zhao XL, Zhao N, Dong XY, Che N, Yao Z, Ma YM, Gu Q, Zong WK and Liu ZY: Promotion of tumor cell metastasis and vasculogenic mimicry by way of transcription coactivation by Bcl-2 and Twist1: A study of hepatocellular carcinoma. Hepatology 54: 1690-1706, 2011.

13. Broggini T, Wustner M, Harms C, Stange L, Blaes J, Thome C, Harms U, Mueller S, Weiler M, Wick W, et al: NDRG1 overexpressing gliomas are characterized by reduced tumor vascularization and resistance to antiangiogenic treatment. Cancer Lett 380: 568-576, 2016.
14. Bittner M, Meltzer P, Chen Y, Jiang Y, Seftor E, Hendrix M, Radmacher M, Simon R, Yakhini Z, Ben-Dor A, et al: Molecular classification of cutaneous malignant melanoma by gene expression profiling. Nature 406: 536-540, 2000.

15. Rüschoff J, Dietel M, Baretton G, Arbogast S, Walch A, Monges G, Chenard MP, Penault-Llorca F, Nagelmeier I, Schlake W, et al: HER2 diagnostics in gastric cancer-guideline validation and development of standardized immunohistochemical testing. Virchows Arch 457: 299-307, 2010.

16. Huang P, Li S, Aronow WS, Wang Z, Nair CK, Xue N, Shen X, Chen $\mathrm{C}$ and Cosgrove D: Double contrast-enhanced ultrasonography evaluation of preoperative Lauren classification of advanced gastric carcinoma. Arch Med Sci 7: 287-293, 2011.

17. Sun B, Zhang S, Zhang D, Yin X, Wang S, Gu Y and Wang Y: Doxycycline influences microcirculation patterns in B16 melanoma. Exp Biol Med (Maywood) 232: 1300-1307, 2007.

18. Langfelder $P$ and Horvath S: WGCNA: An R package for weighted correlation network analysis. BMC Bioinformatics 9: 559, 2008.

19. Subramanian A, Tamayo P, Mootha VK, Mukherjee S, Ebert BL, Gillette MA, Paulovich A, Pomeroy SL, Golub TR, Lander ES and Mesirov JP: Gene set enrichment analysis: A knowledge-based approach for interpreting genome-wide expression profiles. Proc Natl Acad Sci USA 102: 15545-15550, 2005.

20. Bosman FT, Carneiro F, Hruban RH and Theise ND (eds): WHO classification of tumours of the digestive system. Fourth edition. IARC, France, 2010

21. Parkin DM, Bray F, Ferlay J and Pisani P: Global cancer statistics, 2002. CA Cancer J Clin 55: 74-108, 2005.

22. Wöhrer SS, Raderer M and Hejna M: Palliative chemotherapy for advanced gastric cancer. Ann Oncol 15: 1585-1595, 2004.

23. Cheng J, Xie HY, Xu X, Wu J, Wei XY, Su R, Zhang W, Lv Z, Zheng $S$ and Zhou L: NDRG1 as a biomarker for metastasis, recurrence and of poor prognosis in hepatocellular carcinoma. Cancer Lett 310: 35-45, 2011.

24. Nagai MA, Gerhard R, Fregnani JH, Nonogaki S, Rierger RB, Netto MM and Soares FA: Prognostic value of NDRG1 and SPARC protein expression in breast cancer patients. Breast Cancer Res Treat 126: 1-14, 2011.

25. Ureshino H, Murakami Y, Watari K, Izumi H, Kawahara A, Kage M, Arao T, Nishio K, Yanagihara K, Kinoshita H, et al: $\mathrm{N}$-myc downstream regulated gene 1 (NDRG1) promotes metastasis of human scirrhous gastric cancer cells through epithelial mesenchymal transition. PLoS One 7: e41312, 2012.

26. Hendrix MJ, Seftor EA, Meltzer PS, Gardner LM, Hess AR, Kirschmann DA, Schatteman GC and Seftor RE: Expression and functional significance of VE-cadherin in aggressive human melanoma cells: Role in vasculogenic mimicry. Proc Natl Acad Sci USA 98: 8018-8023, 2001.

27. Lee JC, Chung LC, Chen YJ, Feng TH and Juang HH: N-myc downstream-regulated gene 1 downregulates cell proliferation, invasiveness, and tumorigenesis in human oral squamous cell carcinoma. Cancer Lett 355: 242-252, 2014.

28. Iqbal $\mathrm{N}$ and Iqbal N: Human epidermal growth factor receptor 2 (HER2) in cancers: Overexpression and therapeutic implications. Mol Biol Int 2014: 852748, 2014.

29. Yang Y, Liu Y, Guo R, Fu Y, Zhang Z, Zhang P, Zhou P, Wang T, Huang T, Li X and Li C: The novel dithiocarbamate, DpdtC suppresses HER2-overexpressed cancer cells by up-regulating NDRG1 via inactivation of HER2-ERK 1/2 signaling. Sci Rep 8: 3398, 2018.

30. Menezes SV, Sahni S, Kovacevic Z and Richardson DR: Interplay of the iron-regulated metastasis suppressor NDRG1 with epidermal growth factor receptor (EGFR) and oncogenic signaling. J Biol Chem 292: 12772-12782, 2017.

31. Lei YY, Huang JY, Zhao QR, Jiang N, Xu HM, Wang ZN, Li HQ, Zhang SB and Sun Z: The clinicopathological parameters and prognostic significance of HER2 expression in gastric cancer patients: A meta-analysis of literature. World J Surg Oncol 15: 68, 2017.

32. Liu T, Sun B, Zhao X, Gu Q, Dong X, Yao Z, Zhao N, Chi J, Liu N, Sun R and Ma Y: HER2/neu expression correlates with vasculogenic mimicry in invasive breast carcinoma. J Cell Mol Med 17: 116-122, 2013.

This work is licensed under a Creative Commons Attribution-NonCommercial-NoDerivatives 4.0 International (CC BY-NC-ND 4.0) License. 